\title{
A CARTOGRAFIA DIGITAL NA INVESTIGAÇÃO URBANÍSTICA DO PATRIMÔNIO CULTURAL: a área central da cidade do Rio de Janeiro
}

\section{DIGITAL CARTOGRAPHY IN THE URBANISTIC RESEARCH OF CULTURAL HERITAGE: the city of Rio de Janeiro's central area}

\author{
A. Guilherme M. M. de Mattos \& B. Andréa da Rosa Sampaio \\ PPGAU, Universidade Federal Fluminense, Brasil. \\ guilemmm@hotmail.com \\ andreasampaio@id.uff.br
}

\begin{abstract}
RESUMO
O presente trabalho tem como objetivo destacar o potencial das cartografias digitais na investigação dos processos de transformação das cidades, com foco na salvaguarda de bens culturais edificados. Para tanto, adota-se como objeto a Rua da Carioca, na Área Central da Cidade do Rio de Janeiro, cujo processo de transformação perpassa ações de renovação urbana e salvaguarda do patrimônio. A abordagem metodológica centrada nos estudos de morfologia urbana assume a configuração urbana contemporânea como uma amálgama de forças sociais e econômicas incidentes sobre o espaço físico ao longo do tempo. Busca-se evidenciar como o suporte cartográfico digital propicia uma melhor compreensão dos conflitos urbanísticos, pela leitura comparativa dos cadastros históricos e projetos de reurbanização, correlacionada às informações relativas ao patrimônio cultural edificado. Para explorar as potencialidades da cartografia digital, serão investigados os projetos urbanísticos e as ações de proteção incidentes no conjunto arquitetônico da Rua da Carioca.
\end{abstract}

Palavras-chave: cartografia digital, morfologia urbana, patrimônio cultural, Rio de Janeiro.

Linha de Investigação: 1: Cidade e projeto.

Tópico: História urbana e história do urbanismo

\section{ABSTRACT}

The following paper intends to highlight the potential of digital cartography in the study of cities' transformation processes, focusing on the conservation of built cultural heritage. Therefore, Rua da Carioca, in the city of Rio de Janeiro's Central Area, is selected as a study object, whose transformation process entails both urban renewal and heritage protection endeavours. Using the studies of urban morphology as a theoretical and methodological framework, the urban contemporary setting is conceived as an amalgam of the tangible results of social and economic forces that act upon physical space over time. Emphasizing digital cartography as a means for a better understanding of urban conflicts, the heritage protected urban ensemble of Rua da 


\section{XII $\quad$ SÃO PAULO $15 \sim 17 \cdot$ LISBOA $25 \sim 26$ JUN 2020}

Carioca was chosen to demonstrate the potential of these new computer-based platforms in undertaking comparative readings of historic cadastres and urban renewal plans.

Keywords: digital cartography, urban morphology, cultural heritage, Rio de Janeiro.

Research line: 1: City and project.

Topic: Urban History and History of Urbanism

\section{Introdução}

O presente trabalho tem como objetivo destacar o potencial das cartografias digitais na investigação dos processos de transformação das cidades, com foco na salvaguarda de bens culturais edificados. Para tanto, adota-se como objeto o conjunto da Rua da Carioca, na Área Central da Cidade do Rio de Janeiro, cujo processo urbano perpassa ações de salvaguarda e renovação em meio ao histórico embate entre visões conflitantes do futuro da cidade, que se refletem na configuração contemporânea do centro antigo da cidade.

Instigados pelo potencial analítico da cartografia digital para a geração, visualização e difusão de dados urbanísticos e sobre o patrimônio cultural, busca-se refletir sobre o papel da cartografia como um instrumento de representação de dados urbanos, cujo potencial transcende à mera ilustração de dados, sendo uma potente ferramenta de análise e síntese para questões urbanísticas, incluindo as relacionadas ao patrimônio cultural urbano e seus instrumentos para conservação.

No entanto, conforme alerta Costa (2007), a crescente capacidade de produzir e tratar a informação demanda uma "capacidade de síntese sobre a disponibilidade ilimitada de informação, seja histórica ou geográfica, sob o risco de não produzir nem história nem geografia". Corrobora-se com a visão desse arquiteto e pesquisador, de que o desafio crucial que enfrentamos como investigadores é sintetizar e dar sentido a quantidades de informação próprias de um mundo sobremoderno ${ }^{1}$, e não somente dotar-se da capacidade de ordenação desta informação (Costa, 2007:27).

Além das questões relativas ao acesso à crescente profusão de dados, cabe uma reflexão sobre aspectos epistemológicos da cartografia, a partir do reconhecimento do papel dos mapas como imagens dotadas de códigos específicos, definidos historicamente, que não devem ser percebidos como representações passivas do mundo, mas sim como imagens refratadas que contribuem para o diálogo em um mundo socialmente construído (Harley, 1988/2001).

Concebendo-se a cartografia tanto como produto como instrumento, discute-se o potencial das cartografias digitais para empreender uma leitura urbanística e cultural do processo urbano, propiciando a compreensão da conjuntura de grandes transformações da cidade e do processo de patrimonialização, ao longo de seu processo histórico até a contemporaneidade.

Como suporte para essa investigação, adota-se uma abordagem metodológica centrada nos estudos de morfologia urbana, compreendendo a configuração urbana contemporânea como uma amálgama dos resultados tangíveis de forças sociais e econômicas que incidem sobre o espaço físico ao longo do tempo.

\footnotetext{
${ }^{1}$ Costa (2007) refere-se ao conceito de sobremodernidade de Marc Augé (1994), num contexto de superabundância espacial, que nos impõe uma quantidade imensurável de informações sobre o espaço, simultaneamente à redução das distâncias através de sistemas de comunicação. Augé, Marc (1994): Não lugares: introdução a uma antropologia da supermodernidade. Campinas: Papirus.
} 


\section{SÃO PAULO15 17 LISBOA $25 \sim 26$ JUN 2020

Nesse sentido, o presente trabalho perpassa reflexões sobre a cartografia como ferramenta e suas aplicações na investigação urbanística, focando nas relações do patrimônio cultural e da morfologia urbana, buscando contribuir para a reflexão sobre instrumentos metodológicos para a investigação urbanística, ressaltando a relevância da incorporação do estudo da história urbana, fundamentados no argumento de Panerai (2006), de que "o estudo do conjunto da estrutura urbana só se concebe em sua dimensão histórica".

Adota-se a cartografia como estratégia metodológica e ferramenta para tornar legível o emaranhado de parâmetros urbanísticos, projetos urbanos e normas de proteção ao patrimônio incidentes sobre o tecido urbano. Busca-se evidenciar como o suporte cartográfico digital pode ensejar uma melhor compreensão dos conflitos urbanísticos, por meio de uma leitura comparativa dos cadastros históricos e projetos de reurbanização, articulada às informações relativas ao patrimônio edificado. Para explicitar as potencialidades da cartografia digital nesses estudos, serão investigados os projetos urbanísticos e as ações de proteção que incidiram ao longo do processo histórico do conjunto da Rua da Carioca.

\section{A cartografia aplicada à investigação urbanística}

Em reflexão sobre a forma territorial e sua captura pela cartografia, Corboz (1983/2004) afirma o estatuto paradoxal do mapa, que busca exaustivamente a exatidão e, no entanto, necessita escolher os dados. Todo mapa é, portanto, um filtro, calibrado em função de uma série de variáveis. Nesse sentido, cabe aqui refletir brevemente sobre aspectos chaves para problematizar a utilização de mapas, de modo a estabelecer um lastro conceitual e uma compreensão crítica sobre sua aplicação em investigação urbanística.

Sobre o objeto a ser representado, o território, Corboz (1983/2004) também ilumina sua compreensão, considerando sua ancestralidade, sobrecarregado com numerosos vestígios do passado, o comparando com um palimpsesto, continuamente apto a ser reescrito. Compreender sua estratificação é importante para saber intervir, para tanto é fundamental o aporte da cartografia histórica cotejada com o cadastro atual.

Conforme discutido em Sampaio e Oliveira (2018), a cidade do Rio de Janeiro dispõe de um vasto acervo cartográfico, reunido nos acervos institucionais, tanto físicos quanto digitais, tal como exposto por Czajkowski $(2000)^{2}$. Knauss (1997) aborda o tratamento cartográfico de uma seleção de mapas históricos da cidade, em que sublinha a variedade de conceitos espaciais em função do desenvolvimento da técnica de mapeamento, a partir das finalidades das bases para projetos de intervenção urbanística. Nesta reflexão, Knauss (1997) define a cartografia como produto da representação do espaço, conceitualmente demarcada e condicionada historicamente. Portanto, "antes de se indagar os atributos técnicos de um mapa, é preciso questionar as bases de sua construção conceitual” (Knauss, 1997:138).

Com a ampliação do acesso à informação cartográfica da cidade, com a digitalização de acervos e da base cadastral atual ${ }^{3}$, faz-se necessário a realização de estudos baseados nesse acervo documental que articulem os nexos dos diferentes processos imbricados na cidade, cuja documentação encontra-se pulverizada. Tal leitura demanda a contextualização não só da conjuntura urbana, mas da documentação cartográfica propriamente.

\footnotetext{
${ }^{2}$ A exposição realizada no Rio de Janeiro trazia registros da evolução dos mapas realizados para a cidade. Vide catálogo em Czajkowski (Coord.) (2000). Do Cosmógrafo ao Satélite - Mapas da Cidade do Rio de Janeiro. Catálogo da Exposição. Rio de Janeiro: $\mathrm{SMU}$, Centro de Arquitetura e Urbanismo.

${ }^{3}$ As atuais bases cartográficas georreferenciadas estão disponíveis online no Portal Data Rio. Mapas históricos podem ser acessados online principalmente nos acervos digitais da Biblioteca Nacional e Arquivo Nacional.
} 


\section{SÃO PAULO15 17 LISBOA $25 \sim 26$ JUN 2020

A linguagem cartográfica pode ser interpretada como um exercício de "conhecimento é poder", segundo Harley (1988/ 2001), ao investigar as imagens cartográficas em termos de sua influência política na sociedade, a partir de uma perspectiva histórica. Ainda no final da década de 1980, o autor enquadra a cartografia no mundo social, para além de sua corrente inscrição como ciências exatas. Para Harley, os mapas são um modo de conceber, articular e estruturar o mundo humano, em uma linguagem que não é neutra, tanto em termos da seletividade de seu conteúdo, quanto em seus estilos de representação. Como o historiador, o cartógrafo sempre desempenhou um papel retórico na definição das configurações de poder na sociedade e no registro de suas manifestações na paisagem visível.

Há necessidade de releituras dessas questões em função da maior inserção da cartografia no cotidiano da sociedade atual, sobretudo, a cartografia digital, a partir da difusão dos aplicativos digitais. As cartografias interativas, em diversos temas e com ferramentas de participação social, vêm revolucionando o debate, sendo uma pauta importante de estudo. Discutindo o legado conceitual do Harley, Rose-Redwood (2015), problematiza essa questão, uma vez que os mapeamentos digitais contemporâneos contam frequentemente com uma multiplicidade de intervenções autorais que são o resultado do trabalho por vezes voluntário, tanto de novatos e especialistas, suscitando uma linha difusa entre o cartógrafo e os usuários do mapa.

No caso de estudos sobre patrimônio cultural, para além da catalogação dos bens culturais, e do conhecimento das normas vigentes, é crucial lidar com esses dados criticamente, estudando o contexto urbanístico e a dinâmica urbana da área, uma vez que há muitos casos em que o patrimônio cultural se encontra protegido somente no papel, como o da rua da Carioca que será discutido.

\subsection{A Cartografia Digital e o Geoprocessamento}

O avanço tecnológico informacional também se reflete nos campos do urbanismo e do planejamento urbano, que paulatinamente vem incorporando ferramentas advindas do campo da geografia, para representar e analisar o meio urbano. Neste panorama, as técnicas de geoprocessamento e os Sistemas de Informação Geográficas, ou SIGs, tornam-se aliados indispensáveis para análises do espaço urbano, permitindo uma leitura integrada do meio ambiente natural e modificado pelo homem, a partir de uma racionalização de recursos informacionais em bases cartográficas digitais. Segundo Câmara et al. (2001), o geoprocessamento é a disciplina do conhecimento que utiliza de técnicas matemáticas e computacionais para o tratamento de informação geográfica. Uma variada gama de tecnologias que se inserem neste campo, desde as técnicas de sensoriamento remoto, com registro de imagens do meio terrestre por meio de satélites; passando pelo sistema de posicionamento global - ou GPS; até chegar nos complexos Sistemas de Informações Geográficas (Carvalho, Pina e Santos, 2000). Os SIGs são plataformas computacionais empregadas no entendimento de fatos e fenômenos que ocorrem no espaço geográfico, e reconhecidas pela sua potencialidade de agregar um grande acervo de dados convencionais oriundos de fontes diversas em um único banco informacional associado às representações cartográficas digitais.

A associação entre esses dados de natureza distintas configuram o processo de georreferenciamento das informações, que além da inserção de dados alfanuméricos à pontos ou demarcações geográficas, possibilitam também a anexação ao banco de dados de cartografias coletadas, tais como cadastros históricos e plantas de projetos urbanos, com uma adequada superposição à cartografia contemporânea. Logo, o SIG demonstra-se como um instrumento altamente vantajoso no campo do urbanismo, uma vez que grande parte do arcabouço de representação da disciplina é por meio de mapas e plantas em duas 



\section{SÃO PAULO15 17 LISBOA $25 \sim 26$ JUN 2020}

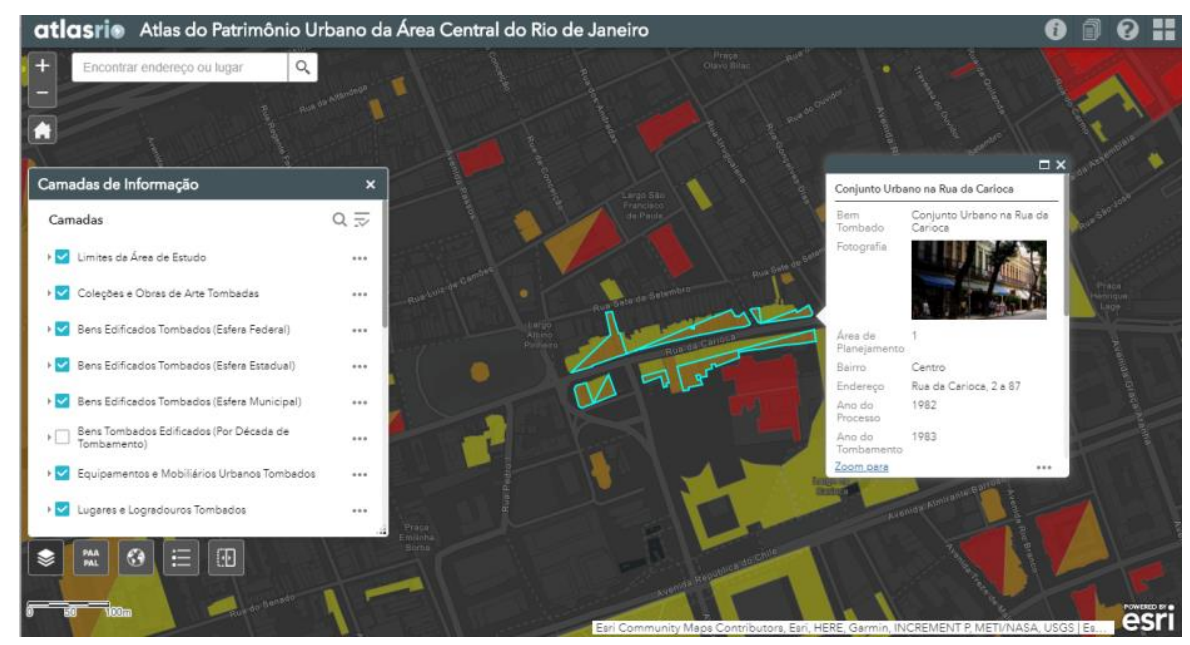

Fig. 01 Mapa Interativo: Atlas do Patrimônio Urbano da Área Central do Rio de Janeiro, no ArcGis Online. Fonte: Autores.

\section{Rua da Carioca, entre a preservação e renovação: uma investigação morfológica a partir da cartografia digital}

\subsection{Rua da Carioca: formação e consolidação do tecido urbano}

Os embates entre os anseios por renovação urbana e as ações de salvaguarda patrimonial têm um destaque especial no processo de tombamento da Rua da Carioca, conjunto edificado de modestas proporções formado por um casario de linguagem neoclássica e eclética da virada do século XX, que reflete a mistura de atividades, cores, e estilos arquitetônicos que compõem a ambiência histórica da Área Central da Cidade do Rio de Janeiro. A Carioca, como via pública, tem suas origens na antiga Rua do Piolho, que no século XVIII ligava o outrora Largo de Santo Antônio (hoje da Carioca) às terras que hoje compõem as imediações da Praça Tiradentes e do Campo de Santana.

Registrada por Thomas Ender, em 1818, a rua era representativa do tecido urbano da Área Central da Cidade, com lotes estreitos e profundos, ocupados por construções predominante térreas, e ocasionalmente pontuada por sobrados e telhados com camarinhas. A configuração seria a mesma no último quartel do século XIX, conforme verificado em uma das primeiras cartografias cadastrais da cidade de 1870 (Figura 02, organizada por Leopoldo José da Silva para o Ministério da Agricultura, Comércio e Obras Públicas). As casas térreas permaneceriam compondo o skyline da rua, tal como registrado no Mappa Architectural de 1874 (levantado pelo engenheiro Rocha Fragoso). A despeito de ser a Capital imperial, persistiam ares coloniais à cidade do Rio de Janeiro. 

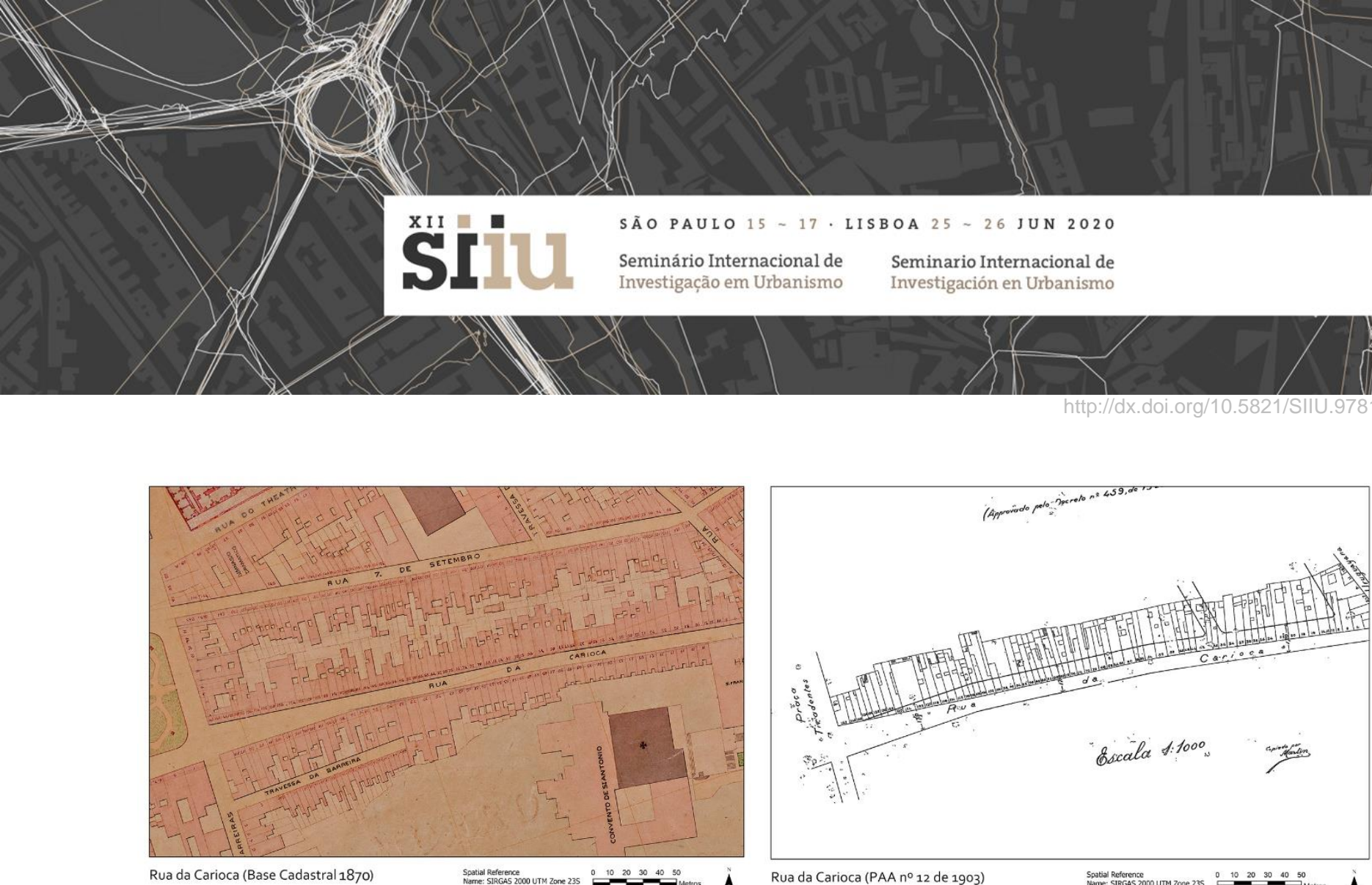

Fig. 02 Rua da Carioca (Base Cadastral de 1870 e PAA no 12 de 1903). Fonte: Arquivo Nacional e SMU-RJ, editados no ARCGIS.

A proclamação da República, e os desejos transformadores da elite da cidade, dariam uma nova fisionomia ao seu núcleo urbano original, sendo a Rua da Carioca um dos objetos das intervenções urbanísticas do prefeito Pereira Passos (1902-1906). Nesta administração, surgem os primeiros Projetos Aprovados de Alinhamento e Loteamento (PAA e PAL) da cidade, ${ }^{5}$ dentre eles o que previa o alargamento da Rua da Carioca (PAA no 12 de 1903, Figura 02), para os seus atuais 17 metros de largura. Nesta intervenção, as edificações do seu lado ímpar, cujos fundos que margeiam o Morro de Santo Antônio, seriam mantidas. À ocasião, as casas térreas já haviam sido substituídas por um correr de sobrados de dois pavimentos, com simples fachadas neoclássicas. Já o seu lado par seria totalmente demolido, dando lugar a um novo alinhamento e novas construções com ornamentadas fachadas ecléticas. Nas décadas seguintes, a Carioca consolidou-se como um logradouro com vocação excepcional para os comércios e serviços da capital, destacando-se nela a presença de estabelecimentos voltados para o lazer, como os bares e os cinemas. Seria esta ambiência, com suas atividades, que viria a ser ameaçada por novos projetos urbanos de meados do século XX.

Em 1941, no âmbito da Prefeitura do Distrito Federal, o arquiteto Saboya Ribeiro produziria o projeto para a Urbanização da Esplanada do Santo Antônio, cujo Morro seria desmontado conforme sugestões do Plano Agache, de 1930. Neste novo projeto (PAA no 3612, Figura 03), uma ampla avenida cruzaria o velho núcleo urbano - a Avenida Diagonal - ladeada por edificações verticalizadas com 7 pavimentos. Embora a Rua da Carioca não fosse diretamente afetada pelo eixo da Diagonal, o seu tecido estava fadado a destruição com a demolição do Morro de Santo Antônio e pela proposta da Avenida "E", de 27 metros de largura, que ligaria o Largo de São Francisco de Paula à prevista Praça Santo Antônio. A Carioca seria também alargada, para 25 metros, conforme o projeto de alinhamento de 1943 (PAA no 3910, Figura 03). O loteamento previsto para o lado par da Rua da Carioca alterou o gabarito do conjunto para 10 pavimentos, que em muito excedia a volumetria existente de três pisos. Os impactos reais do projeto, contudo, foram mínimos, visto que pouco foi executado desta proposta.

\footnotetext{
5 Os projetos aprovados de alinhamento e loteamento, podem ser consultados online pelo website da SMU-RJ: $<$ http://www2.rio.rj.gov.br/smu/acervoimagens/principal.asp>.
} 


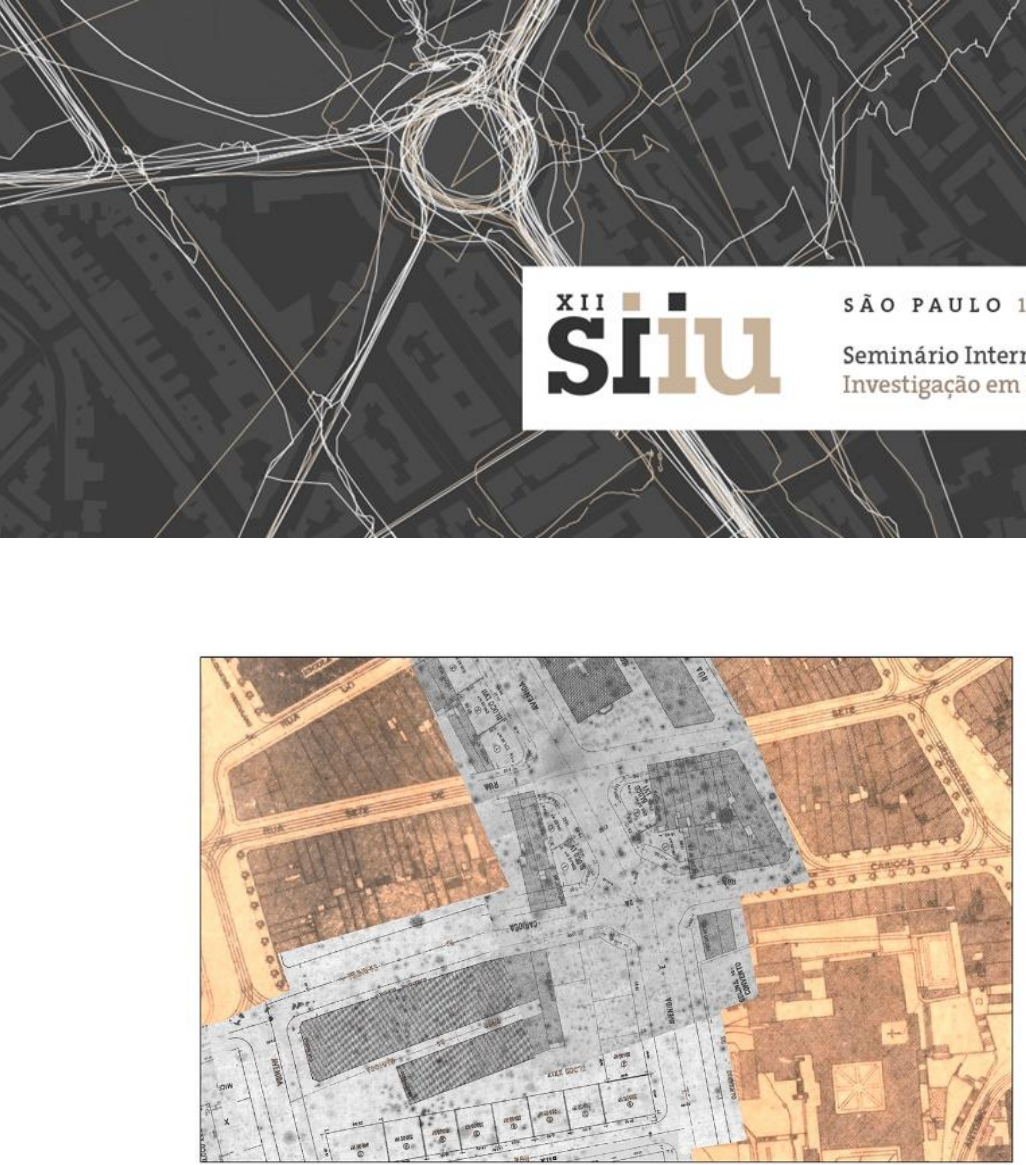

Rua da Carioca (PAA n 3612 de 1941 sobre Base Cadastral de 1935)

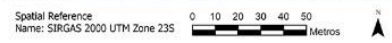

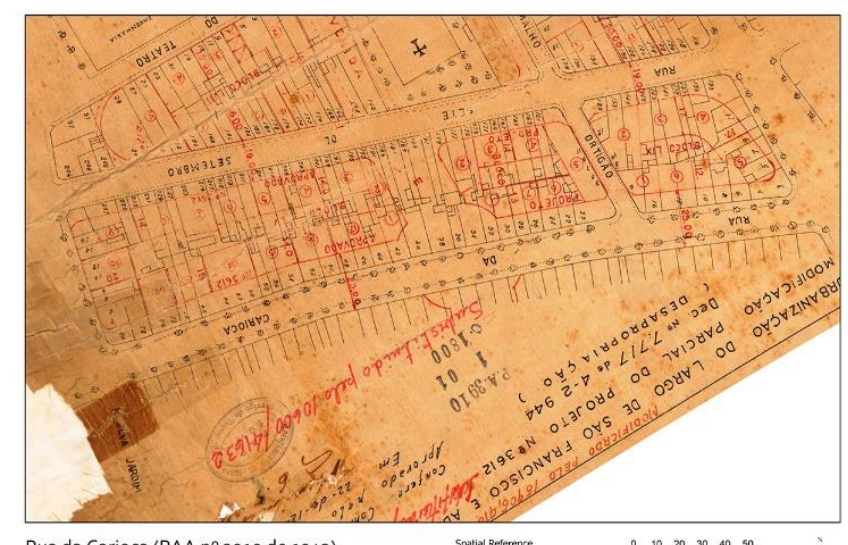

Rua da Carioca (PAA nº 3910 de 1943)
Seminario Internacional de Investigación en Urbanismo

Fig. 03 Rua da Carioca (PAA no 3612 de 1941 e no 3910 de 1943). Fonte: SMU-RJ, editados no ARCGIS.

A grande ameaça à Rua da Carioca viria com a urbanização proposta para a Esplanada de Santo Antônio pelo arquiteto Affonso Eduardo Reidy, em 1947, e seu grande eixo viário: a Avenida Norte-Sul. A avenida ligaria a Região Portuária à Lapa, cruzando a Rua da Carioca e o vazio do Morro de Santo Antônio. O impacto desta avenida no velho tecido da cidade é melhor apresentado pelo PAA no 5029 de 1949, embora este não chegue a explicitar as proposições para a Rua da Carioca, que ainda permaneceriam seguindo as diretrizes do PAA o 3910 de 1943. Novas modificações seriam realizadas com o PAA o 5408 de 1950, que previa uma nova largura para a Carioca, de 32 metros, reforçadas pelo PAA no 7214 de 1958 (Figura 04), que contempla toda a urbanização da Esplanada. Neste PAA, o lado ímpar da Rua da Carioca é representado como praticamente vazio, sendo a nova margem da via uma parte preservada do Morro de Santo Antônio, isolando o Convento de Santo Antônio e a Igreja de Ordem Terceira de São Francisco da Penitência, ambos tombados pelo órgão de tutela federal - o então SPHAN - em 1938. As intervenções estavam em sintonia com o que era preconizado pela Carta de Atenas do CIAM, de 1933, que recomendava a remoção de casario insalubre e a liberação do entorno de monumentos históricos, destacando-os na paisagem com cinturões de áreas verdes. Já o seu lado par, seria substituído por uma nova quadra de edificações verticalizadas, com galerias de pedestres no térreo.

As propostas de abertura da Av. Diagonal e da Av. Norte-Sul seriam interrompidas com a revogação dos projetos em 1963, durante o governo de Carlos Lacerda, já com a cidade do Rio de Janeiro em sua condição política de Estado da Guanabara. Os impactos devastadores dessas propostas às atividades tradicionais dos conjuntos edificados levariam os comerciantes da área a fundarem a SAARA - Sociedade dos Amigos das Adjacências da Rua da Alfândega, e pressionarem o governo estadual a interromper as propostas de abertura de ambas as avenidas. No caso da Norte-Sul, o seu trecho na Esplanada de Santo Antônio, cujo morro já havia sido demolido, persistiria, iniciando na Lapa e terminando na Rua da Carioca. Os projetos da década de 1960 que incidiam na Rua da Carioca seriam mais respeitosos à sua morfologia original. Os PAAs no 8353 e 8382 de 1966 (Figura 04) preservam o alinhamento original do lado ímpar da via, e limitam seu gabarito a três pavimentos. Para a ligação da Carioca com o trecho mantido da Norte-Sul, seriam demolidos os sobrados entre os números 57 e 89. Já no lado par, não há sequer vestígio do eixo da Norte-Sul, embora ainda se previsse um novo alinhamento, conferindo à Rua da Carioca a largura de 28 metros. 


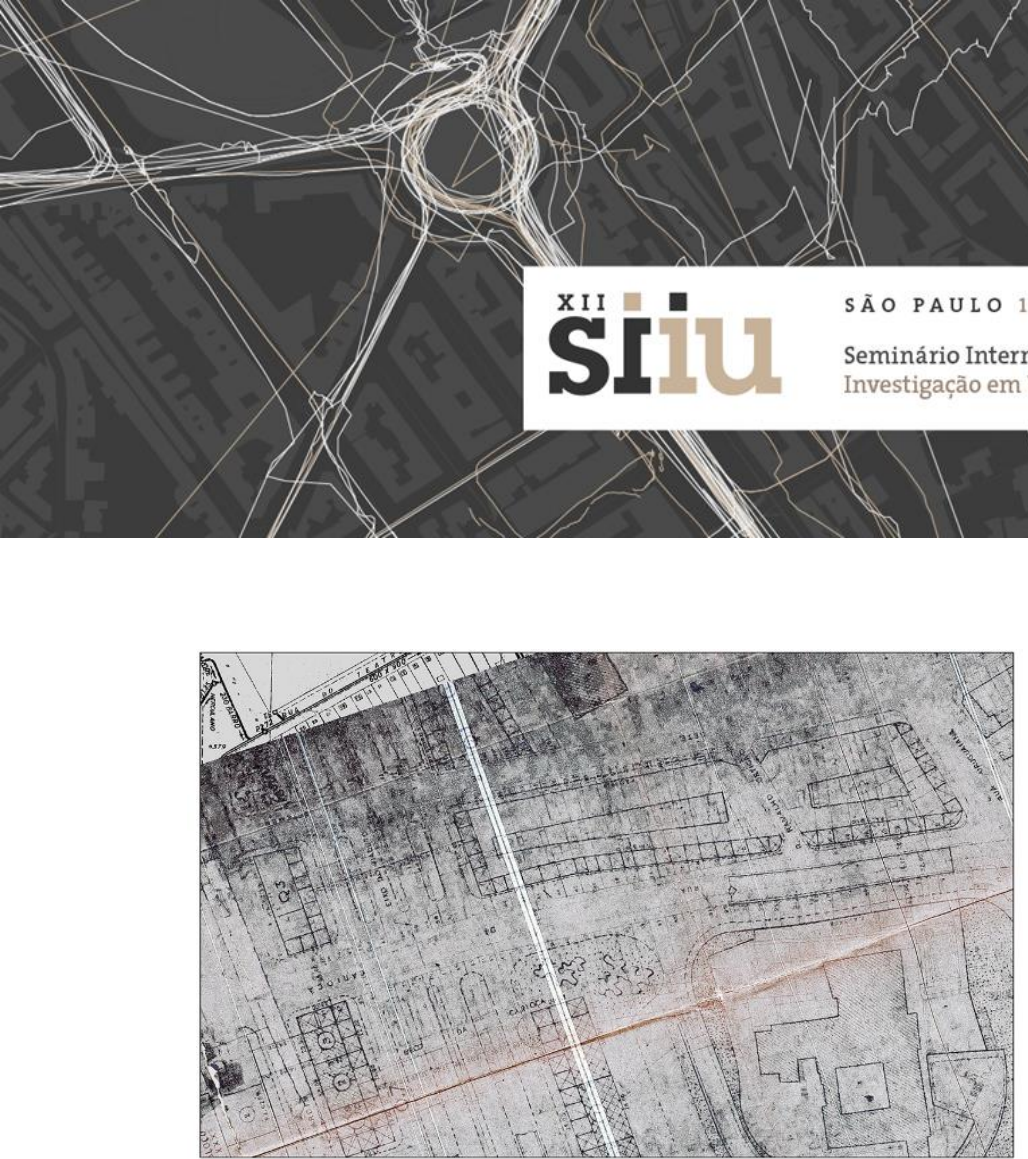

Rua da Carioca (PAA n 7214 de 1958 sobre Base Cadastral de 1953)

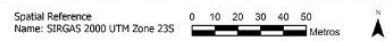

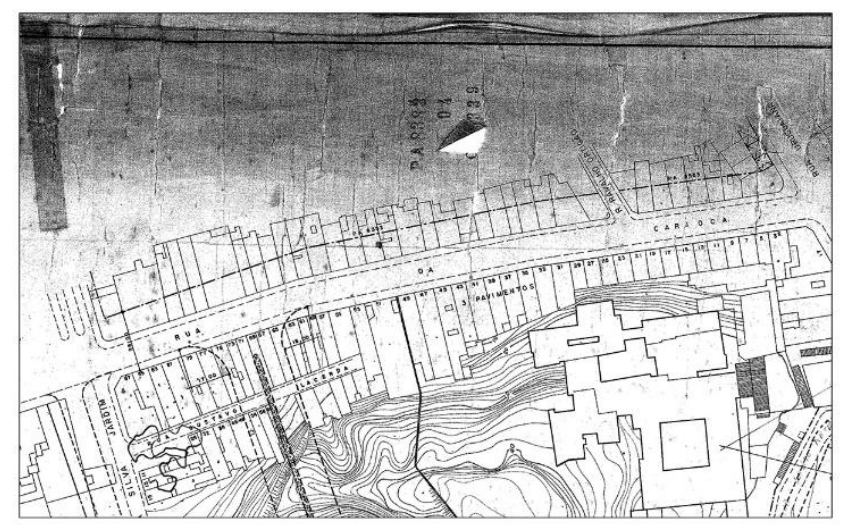

Rua da Carioca (PAA n॰8382 de 1966)
Seminario Internacional de Investigación en Urbanismo

Fig. 04 Rua da Carioca (PAA no 7214 de 1958 e no 8382 de 1966). Fonte: SMU-RJ, editados no ARCGIS.

Em 1970, o fantasma da Avenida Norte-Sul retorna a assombrar o tecido urbano que vai da Rua da Carioca até a Região Portuária, com o PAA no 8944, reforçado pelo PAA no 9091 de 1972 (Figura 05). A avenida voltaria a se estender até as proximidades da Rua Senador Pompeu, atravessando o conjunto edificado do lado par da Rua da Carioca. Nesta nova proposição, os imóveis de número 56 a 68 teriam que ser desapropriados para execução da Avenida, cuja largura da fachada a fachada para os novos lotes urbanizados seria de 40 metros.

\subsection{Rua da Carioca: embates entre a proteção e a renovação urbana}

A partir da década de 1970, exacerbam-se os conflitos entre as proposições urbanas renovadoras e a novas práticas preservacionistas. Novas diretrizes de salvaguarda, consoantes com a Carta de Veneza (1964), e com o conceito de conservação integrada ao desenvolvimento urbano da Declaração de Amsterdã (1975), passavam a permear as ações de proteção dos órgãos de tutela atuantes na cidade do Rio de Janeiro. Desde 1964, a cidade também contava com um órgão em esfera estadual, o antigo DPHA do Estado Guanabara, que daria forma ao INEPAC - Instituto Estadual do Patrimônio Cultural, com a fusão da Guanabara com o Estado do Rio de Janeiro, em 1975. O INEPAC, em sua essência, já contemplava a proteção de bens desconsiderados para a preservação federal, tal como o tombamento do imóvel do Cinema Íris, em 1978.

Reconheciam-se, também, os valores presentes na arquitetura menor que compunha a paisagem histórica da cidade, atrelados às suas atividades tradicionais, formando uma ambiência característica. Neste ponto, destacam-se ações da administração municipal, em fins da década de 1970, como um desdobramento das diretrizes do Plano Urbanístico Básico do Rio de 1977, que vislumbrava a preservação ambiental da cidade, tanto em seus aspectos naturais, quanto àquelas de urbanização histórica. Tal avanço é apontado por Nascimento (2018) como um ponto de inflexão na relação entre patrimônio e planejamento, ao propor a preservação de ambientes urbanos tradicionais como diretriz de planejamento urbano da cidade. Nesse sentido, foi publicado o Decreto Municipal no 1707 de 1978 que limita a altura dos imóveis da Rua da Carioca, em ambos os seus lados, em oito metros. Embora os imóveis não tenham sido legalmente preservados, a limitação do gabarito desestimulava a sua substituição. A segunda ação seria o Projeto do Corredor Cultural, de 1979, primeiro projeto de revitalização para o tecido urbano tradicional de vias estreitas e pequenos 




\section{SÃO PAULO15 17 LISBOA $25 \sim 26$ JUN 2020}

Como contribuição para a reflexão sobre a investigação urbanística, defende-se que ato de projetar o futuro reconheça as ações que a antecederam, servindo como lições para o porvir, e nesta empreitada as investigações com apoio da cartografia digital tornam-se aliadas em uma apreensão global do espaço urbano. Faz-se necessário, portanto, a adoção de ferramentas analíticas que deem conta desse objeto plural que é a cidade, integrando conhecimentos territoriais específicos, e propiciando uma gestão compartilhada. Não se trata simplesmente de dispor da mais avançada tecnologia, mas sim de empreender uma leitura conceitualmente articulada, que contribua para a atualização do arcabouço teórico a partir de perspectivas para novas questões emergentes e socialmente pactuadas.

\section{Bibliografia}

CÂMARA, G. et al. (2001) Introdução à Ciência da Geoinformação. São José dos Campos: INPE.

CARVALHO, M.S., PINA, M.F.R.P. e SANTOS, S.M. (2000). Conceitos Básicos de Sistemas de Informação Geográfica e Cartografia Aplicados à Saúde. Brasília: RIPSA, Ministério da Saúde.

CORBOZ, André (2004). El Territorio como Palimpsesto. En RAMOS, Angel M. Lo Urbano en 20 autores Contemporáneos. (25-34) Barcelona: ETSAB, Edicions UPC. (Texto originalmente publicado em 1983)

COSTA, Francisco de Assis da. (2007). Atlas Histórico de Cidades: a cidade como objetivo de investigação. Cadernos PPG-AU/UFBA, v. 6, (19-29).

HARLEY, J.B. (2001). Maps, Knowledge and Power. In: HARLEY, J.B., The New Nature of Maps: Essays in the History of Cartography (51-81). Baltimore: The Johns Hopkins University Press. (Texto originalmente publicado em 1988)

KNAUSS, Paulo. (1997) Imagem do Espaço, Imagem da História. A representação espacial da cidade do Rio de Janeiro. Tempo, Rio de Janeiro, Vol. 2, $n^{\circ} \quad 3 \quad$ (135-148). $<$ http://www.historia.uff.br/tempo/artigos_livres/artg3-6.pdf>

MATTOS, Guilherme Meirelles M. de (2018). Leituras de Passado, Desenhos de Um Futuro: A Preservação do Patrimônio Cultural Edificado na Área Central do Rio de Janeiro. 2018. Tese (Doutorado em Urbanismo) PROURB, FAU-UFRJ. Rio de Janeiro.

NASCIMENTO, Flavia B. (2018). Corredor Cultural do Rio de Janeiro: debates e combates pelo patrimônio cultural urbano nos anos 1970. Patrimônio e Memória. v. $14 . \quad$ n. $2 . \quad$ (117-139) $<$ http://pem.assis.unesp.br/index.php/pem/article/view/805/1031>

PANERAI, Philippe (2006). Análise Urbana. Brasília: Editora UNB.

ROSE-REDWOOD, Reuben (2015). Deconstructing the Map: 25 years on looking "Beyond" Power? J.B. Harley's Legacy and the Powers of Cartographic World-Making. Cartographica: the International Journal for Geographic Information and Geovisualization 50:1, (54-57)

SAMPAIO, Andrea da R. (2016). Um olhar sobre a história do urbanismo da Área Central do Rio de Janeiro: entre a renovação e a conservação. Revista AGCRJ, 10, (193-212). <http://wpro.rio.ri.gov.br/revistaagcri/ category/numero-10/> 


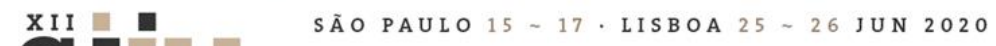

Seminario Internacional de Investigação em Urbanismo

SAMPAIO, Andrea da R.; OLIVEIRA, Ana C. M. (2018) Cartografias da Área Central da cidade do Rio de Janeiro: uma leitura urbanística e cultural do processo urbano. Simposios innovadores: $56 .$. Congreso Internacional de Americanistas. Salamanca 2018. v.19. (543-556) Ediciones Universidad de Salamanca. 